\title{
Network Damage Predicts Clinical Worsening in Multiple Sclerosis
}

\author{
A 6.4-Year Study
}

Maria A. Rocca, MD, Paola Valsasina, MSc, Alessandro Meani, MSc, Elisabetta Pagani, MSc, Claudio Cordani, PT, Chiara Cervellin, PT, and Massimo Filippi, MD

Neurol Neuroimmunol Neuroinflamm 2021;8:e1006. doi:10.1212/NXI.0000000000001006

\section{Abstract}

\section{Objective}

In multiple sclerosis (MS), clinical impairment is likely due to both structural damage and abnormal brain function. We assessed the added value of integrating structural and functional network MRI measures to predict 6.4-year MS clinical disability deterioration.

\section{Methods}

Baseline 3D T1-weighted and resting-state functional MRI scans were obtained from 233 patients with MS and 77 healthy controls. Patients underwent a neurologic evaluation at baseline and at 6.4-year median follow-up (interquartile range $=5.06-7.51$ years). At follow-up, patients were classified as clinically stable/worsened according to disability changes. In relapsing-remitting (RR) MS, secondary progressive (SP) MS conversion was evaluated. Global brain volumetry was obtained. Furthermore, independent component analysis identified the main functional connectivity (FC) and gray matter (GM) network patterns.

\section{Results}

At follow-up, 105/233 (45\%) patients were clinically worsened; 26/157 (16\%) patients with RRMS evolved to SPMS. The treatment-adjusted random forest model identified normalized GM and brain volumes, decreased FC between default-mode networks, increased FC of the left precentral gyrus in the sensorimotor network (SMN), and GM atrophy in the fronto-parietal network (false discovery rate $[\mathrm{FDR}]$-corrected $p=$ range $0.01-0.09$ ) as predictors of clinical worsening (out-of-bag $[\mathrm{OOB}]$ accuracy $=0.74$ ). An expected contribution of baseline disability was also present $($ FDR-p $=0.01)$. Baseline disability, normalized GM volume, and GM atrophy in the SMN (FDR-p = range 0.01-0.09) were independently associated with SPMS conversion $(\mathrm{OOB}$ accuracy $=0.84)$. At receiver operating characteristic analysis, including network MRI variables improved disability worsening $(p=0.05)$ and SPMS conversion $(p=0.02)$ prediction.

\section{Conclusions}

Integration of MRI network measures helped determining the relative contributions of global/ local GM damage and functional reorganization to clinical deterioration in MS.

\author{
Correspondence \\ Prof. Filippi \\ filippi.massimo@hsr.it
}




\section{Glossary}

AUC $=$ area under the curve; BGN = basal ganglia network; DMN = default-mode network; DMT = disease-modifying treatment; EDSS = Expanded Disability Status Scale; FC = functional connectivity; FDR = false discovery rate; fMRI = functional MRI; FPN = fronto-parietal network; GM = gray matter; $\mathbf{H C}=$ healthy control; $\mathbf{I C}$ = independent component; $\mathbf{L V}=$ lesion volume; $\mathbf{M S}=$ multiple sclerosis; $\mathbf{O O B}=$ out of bag; $\mathbf{P P M S}=$ primary progressive MS; $\mathbf{R F}=$ random forest; $\mathbf{R R}=$ relapsing-remitting MS; $\mathbf{R S}$ = resting state; $\mathbf{S B M}=$ source-based morphometry; SMA = supplementary motor area; $\mathbf{S M N}=$ sensorimotor network; $\mathbf{S N}$ = salience network; SPMS = secondary progressive MS; $\mathbf{W M}=$ white matter.

Multiple sclerosis (MS) is the most common inflammatory, demyelinating and neurodegenerative CNS disease characterized by a great interindividual variability. ${ }^{1}$ Now that several disease-modifying treatments (DMTs) are available, ${ }^{2}$ there is an increasing need to identify patients with MS having a more severe disease evolution, to optimize patients' management and increase the benefit/risk ratio.

Conventional MRI revolutionized MS evaluation and was formally included in MS diagnostic criteria. ${ }^{3}$ In treated patients with MS, MRI disease activity measures are combined with clinical evaluation to guide treatment decisions. ${ }^{4}$ However, the predictive value of conventional MRI on subsequent disease course is still debated, with only some studies detecting a significant influence of white matter (WM) lesion burden on disease evolution. ${ }^{5-7}$

A large effort has been spent to improve predictivity of MRI in MS by assessing clinically relevant compartments (i.e., gray matter [GM], strategic WM tracts, and spinal cord) and by applying quantitative techniques, sensitive toward different pathologic substrates. ${ }^{8}$ This helped demonstrate that in patients with established MS and in progressive MS (PMS), GM damage plays a major role in explaining long-term disability and cognitive decline. ${ }^{9-12}$

Brain function depends on not only local processing but also effective global communication and integration of information. Because impaired interaction among the main brain areas may cause disability accumulation in MS, mapping structural and functional brain networks might be clinically relevant. Studies of structural network abnormalities, which decomposed WM lesions and GM maps into distinct patterns covarying across subjects, revealed that a stronger network disruption in these 2 compartments was correlated with severe disability ${ }^{13}$ and was able to predict the subsequent disease course. ${ }^{14,15}$ Resting-state (RS) functional connectivity (FC) network studies showed complex abnormalities in patients with $\mathrm{MS},{ }^{16,17}$ characterized by an early RS FC increase and RS FC decrease in more advanced phases. Abnormal within- and between-network RS FC contributed to explain MS phenotypic variability and cognitive deficits ${ }^{16,18}$ and was able to predict clinical deterioration at medium term, ${ }^{19,20}$ whereas abnormal FC during a psychological stress functional (fMRI) paradigm contributed to explain future GM atrophy. ${ }^{21}$ However, the combined ability of functional and structural network techniques in predicting subsequent clinical worsening of MS was not investigated yet.
In this study, we hypothesized that integrating structural and functional network information may help to identify specific circuits being critical for clinical deterioration in heterogeneous diseases such as MS, and may improve prediction of the subsequent disease course, in terms of disability increase and evolution to a more severe clinical phenotype. To test this, we analyzed volumetric and RS fMRI data from a large MS cohort and mapped abnormalities of the main data-driven functional and structural GM networks. Then, we assessed the added value of integrated structural and functional network MRI measures to predict clinical disability deterioration and conversion to secondary progressive (SP) MS over a 6.4-year follow-up.

\section{Methods}

\section{Standard Protocol Approvals, Registrations, and Patient Consents}

Approval was received from the local ethical standards committee on human experimentation (protocol ID: FISM 2008/ $\mathrm{R} / 13$ ); written informed consent was obtained from all subjects before study participation.

\section{Subjects}

Recruited subjects are part of a prospective cohort at Hospital San Raffaele. Patients are assessed clinically at the MS Center at least once per year and are offered the opportunity to undergo research brain MRI. Inclusion criteria are reported in the e-Methods (links.lww.com/NXI/A486). For the current analysis, we selected patients with a clinical follow-up $\geq 3$ years from MRI acquisition. The final cohort included 233 patients with MS (90/143 males $/$ females; mean age $=42.3$ years, $S D=$ 10.8 years): there were 157 relapsing-remitting (RR) MS, 59 SPMS, and 17 primary progressive (PP) MS. ${ }^{22}$ Crosssectional MRI from 77 matched healthy controls (HCs) $(35 / 42 \mathrm{males} /$ females; mean age $=41.0$ years, $\mathrm{SD}=14.5$ years) were also analyzed. Part of baseline MRI/clinical evaluations was previously published. ${ }^{16,23}$

\section{Clinical Assessment}

At baseline, a complete neurologic evaluation was performed in patients with MS, with rating of the Expanded Disability Status Scale (EDSS) score ${ }^{24}$ and DMT recording. The followup neurologic assessment was performed after a median of 6.4 years (interquartile range $=5.06-7.51$ years) and included EDSS score rating, occurrence of clinical relapses, and DMT changes (binary coded). At follow-up, patients were clinically 
Table 1 Main Demographic, Clinical, and Conventional MRI Measures of HCs and Patients With MS (as a Whole and According to the Clinical Phenotype)

\begin{tabular}{|c|c|c|c|c|c|c|c|c|}
\hline & $\begin{array}{l}\text { HCs } \\
(n=77)\end{array}$ & $\begin{array}{l}\text { Patients with MS } \\
(n=233)\end{array}$ & $\begin{array}{l}p \\
\text { Value }^{a}\end{array}$ & $\begin{array}{l}\text { Patients with RRMS } \\
(n=157)\end{array}$ & $\begin{array}{l}\text { Patients with PMS } \\
(n=76)\end{array}$ & $\begin{array}{l}p \\
\text { Value }^{b}\end{array}$ & $\begin{array}{l}p \\
\text { Value }\end{array}$ & Value $^{d}$ \\
\hline Men (\%) & $35(45)$ & $90(39)$ & $0.29^{e}$ & $62(40)$ & $28(37)$ & $0.38^{e}$ & $0.28^{\mathrm{e}}$ & $0.70^{\mathrm{e}}$ \\
\hline Women (\%) & $42(55)$ & $143(61)$ & & $95(60)$ & $48(63)$ & & & \\
\hline Mean age (SD) [y] & $41.0(14.5)$ & $42.3(10.8)$ & $0.49^{f}$ & $39.3(9.8)$ & $48.4(10.2)$ & $0.35^{f}$ & $<0.001^{f}$ & $<0.001^{f}$ \\
\hline $\begin{array}{l}\text { Median disease duration } \\
\text { (IQR) [y] }\end{array}$ & - & $13.0(7.5-18.0)$ & - & $11.0(5.8-16.1)$ & $17.0(12.5-24.0)$ & - & - & $<0.001^{\mathrm{g}}$ \\
\hline Median EDSS score (IQR) & - & $2.5(1.5-5.0)$ & - & $2.0(1.5-2.5)$ & $6.0(5.3-6.5)$ & - & - & $<0.001^{\mathrm{g}}$ \\
\hline Baseline DMT & - & & - & & & - & - & $<0.001^{\mathrm{e}}$ \\
\hline No DMT (n) & & 37 & & 11 & 26 & & & \\
\hline $\begin{array}{l}\text { Interferons }(\mathbf{n}) \text { /glatiramer } \\
\text { acetate }(n)\end{array}$ & & $106 / 44$ & & $85 / 33$ & $21 / 11$ & & & \\
\hline Natalizumab (n) & & 16 & & 13 & 3 & & & \\
\hline Fingolimod (n) & & 13 & & 12 & 1 & & & \\
\hline \multicolumn{9}{|l|}{ Immunosuppressants: } \\
\hline Azathioprine (n) & & 10 & & 1 & 9 & & & \\
\hline Cyclophosphamide (n) & & 2 & & 0 & 2 & & & \\
\hline Methotrexate (n) & & 1 & & 1 & 0 & & & \\
\hline Mitoxantrone (n) & & 4 & & 1 & 3 & & & \\
\hline $\begin{array}{l}\text { Median follow-up duration } \\
\text { (IQR) [y] }\end{array}$ & - & $6.4(5.1-7.5)$ & - & $6.5(5.5-7.6)$ & $53.3(3.7-7.1)$ & - & - & $0.001^{g}$ \\
\hline Mean ARR at follow-up (SD) & - & $0.07(0.14)$ & - & $0.08(0.15)$ & $0.04(0.11)$ & - & - & $0.02^{h}$ \\
\hline DMT change & - & & - & & & - & - & $0.83^{i}$ \\
\hline Yes (\%) & & $111(47)$ & & $76(48)$ & $35(46)$ & & & \\
\hline No (\%) & & $122(53)$ & & $81(52)$ & $41(54)$ & & & \\
\hline $\begin{array}{l}\text { Median T2 LV } \\
(\text { IQR) }[\mathrm{mL}]\end{array}$ & $\begin{array}{l}0.2 \\
(0.08-0.8)\end{array}$ & $6.2(2.5-13.8)$ & $<0.001^{j}$ & $4.5(1.9-8.5)$ & $14.0(5.4-24.3)$ & $<0.001^{\mathrm{j}}$ & $<0.001^{j}$ & $<0.001^{j}$ \\
\hline $\begin{array}{l}\text { Median T1 LV } \\
(\mathrm{IQR})[\mathrm{mL}]\end{array}$ & - & $4.3(9.4-10.0)$ & - & $2.8(1.1-5.8)$ & $9.2(3.9-17.7)$ & - & - & $<0.001^{j}$ \\
\hline Mean NBV (SD) [mL] & $1,568(81)$ & $1,489(108)$ & $<0.001^{\mathrm{j}}$ & $1,514(102)$ & $1,436(102)$ & $<0.001^{j}$ & $<0.001^{j}$ & $<0.001^{j}$ \\
\hline Mean NGMV (SD) [mL] & $732(49)$ & $672(80)$ & $<0.001^{j}$ & $690(75)$ & $633(75)$ & $<0.001^{j}$ & $<0.001^{\mathrm{j}}$ & $0.002^{j}$ \\
\hline Mean NWMV (SD) [mL] & $836(43)$ & $817(48)$ & $<0.001^{\mathrm{j}}$ & $824(43)$ & $803(56)$ & $0.04^{\mathrm{j}}$ & $<0.001^{j}$ & $0.08^{j}$ \\
\hline Mean NDGMV (SD) [mL] & $52(4)$ & $47(6)$ & $<0.001^{\mathrm{j}}$ & $48(5)$ & $44(7)$ & $<0.001^{j}$ & $<0.001^{\mathrm{j}}$ & $<0.001^{j}$ \\
\hline \multicolumn{9}{|c|}{$\begin{array}{l}\text { Abbreviations: ARR = annualized relapse rate; DMT = disease-modifyin } \\
\text { interquartile range; LV = lesion volume; MS = multiple sclerosis; NBV = } \\
\text { normalized gray matter volume; NWMV = normalized white matter v } \\
\text { sclerosis. } \\
\text { a Patients with MS vs HCs. } \\
\text { b Patients with RRMS vs HCs. } \\
\text { c Patients with PMS vs HCs. } \\
\text { d Patients with PMS vs RRMS. } \\
\text { e Chi-square test. } \\
\text { ' Two-sample test. } \\
\text { g Mann-Whitney U test. } \\
\text { h Negative binomial regression model. } \\
\text { ' Univariate logistic regression model, adjusted for follow-up duration. } \\
\text { j Age- and sex-adjusted linear models. }\end{array}$} \\
\hline
\end{tabular}


Table 2 Demographic, Clinical, and Conventional MRI Measures of Patients With MS, Divided According to Clinical Worsening at Follow-up, and of Patients With RRMS, Divided According to Conversion to SPMS at Follow-up

\begin{tabular}{|c|c|c|c|c|c|c|}
\hline & $\begin{array}{l}\text { Clinically stable } \\
\text { MS }(n=128)\end{array}$ & $\begin{array}{l}\text { Clinically } \\
\text { worsened MS ( } n= \\
105)\end{array}$ & $\begin{array}{l}p \\
\text { Value }^{a}\end{array}$ & $\begin{array}{l}\text { Patients with RRMS not } \\
\text { converting to SPMS }(n=131)\end{array}$ & $\begin{array}{l}\text { Patients with RRMS } \\
\text { converting to SPMS }(n=26)\end{array}$ & $\begin{array}{l}p \\
\text { Value }\end{array}$ \\
\hline Men (\%) & $44(34)$ & $46(44)$ & 0.12 & $46(35)$ & $16(62)$ & 0.009 \\
\hline Women (\%) & $84(66)$ & $59(56)$ & & $85(65)$ & $10(38)$ & \\
\hline Mean baseline age (SD) [y] & $39.5(10.5)$ & $45.6(10.2)$ & $<0.001$ & $38.2(9.5)$ & $44.8(9.4)$ & 0.002 \\
\hline $\begin{array}{l}\text { Median baseline disease } \\
\text { duration (IQR) [y] }\end{array}$ & $11.8(5.7-16.7)$ & $15.3(10.0-20.0)$ & 0.003 & $10.2(5.7-15.9)$ & $13.9(9.5-17.0)$ & 0.17 \\
\hline $\begin{array}{l}\text { Median baseline EDSS } \\
\text { score (IQR) }\end{array}$ & $2.0(1.5-3.5)$ & $4.0(2.0-6.0)$ & $<0.001$ & $1.5(1.5-2.0)$ & $3.0(2.0-4.0)$ & $<0.001$ \\
\hline $\begin{array}{l}\text { Baseline phenotype } \\
\text { (RRMS/progressive MS) }\end{array}$ & $105 / 23$ & $52 / 53$ & $<0.001$ & - & - & - \\
\hline Baseline DMT & & & 0.68 & & & 0.85 \\
\hline No (\%) & $22(17)$ & $15(14)$ & & $9(7)$ & $2(8)$ & \\
\hline Yes (\%) & $106(33)$ & $90(86)$ & & $122(93)$ & $24(92)$ & \\
\hline $\begin{array}{l}\text { Median follow-up } \\
\text { duration (IQR) [y] }\end{array}$ & $6.3(4.8-7.2)$ & $6.5(5.3-7.7)$ & $0.22^{\mathrm{b}}$ & $6.5(5.3-7.6)$ & $6.8(5.8-7.6)$ & $0.44^{\mathrm{b}}$ \\
\hline $\begin{array}{l}\text { Mean ARR at follow-up } \\
\text { (SD) }\end{array}$ & $0.07(0.15)$ & $0.07(0.12)$ & 0.69 & $0.09(0.15)$ & $0.07(0.11)$ & 0.53 \\
\hline DMT change & & & 0.006 & & & 0.01 \\
\hline Yes (\%) & $50(39)$ & $61(58)$ & & $57(44)$ & $19(73)$ & \\
\hline No (\%) & $78(61)$ & $44(42)$ & & $74(56)$ & $7(27)$ & \\
\hline Median T2 LV (IQR) [mL] & $4.7(2.0-9.3)$ & $8.1(3.1-18.4)$ & 0.002 & $4.2(1.7-8.0)$ & $6.2(2.5-12.5)$ & 0.22 \\
\hline Median T1 LV (IQR) [mL] & $2.8(1.1-6.1)$ & $5.6(2.1-13.3)$ & 0.001 & $2.4(1.0-5.6)$ & $4.4(1.5-9.9)$ & 0.20 \\
\hline Mean NBV (SD) [mL] & $1,518(102)$ & $1,453(104)$ & $<0.001$ & $1,527(101)$ & $1,451(80)$ & $<0.001$ \\
\hline Mean NGMV (SD) [mL] & $696(76)$ & $643(74)$ & $<0.001$ & $701(75)$ & $639(55)$ & $<0.001$ \\
\hline Mean NWMV (SD) [mL] & $822(47)$ & $810(50)$ & 0.05 & $826(43)$ & $812(39)$ & 0.12 \\
\hline Mean NDGMV (SD) [mL] & $48(5)$ & $45(6)$ & $<0.001$ & $48(5)$ & $47(4)$ & 0.09 \\
\hline \multicolumn{7}{|c|}{$\begin{array}{l}\text { Abbreviations: ARR = annualized relapse rate; DMT = disease-modifying treatment; EDSS = Expanded Disability Status Scale; IQR = interquartile range; LV = } \\
\text { lesion volume; MS = multiple sclerosis; NBV = normalized brain volume; NDGMV = normalized deep gray matter volume; NGMV = normalized gray matter } \\
\text { volume; NWMV = normalized white matter volume; RRMS = relapsing-remitting multiple sclerosis; SPMS = secondary progressive multiple sclerosis. } \\
\text { a Univariate logistic regression model, adjusted for follow-up duration. } \\
\text { b Mann-Whitney U test. }\end{array}$} \\
\hline
\end{tabular}

worsened if they had an EDSS score increase $\geq 1.0$ when the baseline EDSS score was $<6.0, \geq 0.5$ when the baseline EDSS score was $\geq 6.0,^{9}$ or $\geq 1.5$ if the baseline score EDSS was $0 .^{25}$ EDSS score changes were confirmed after a 3-month, relapsefree period. In RRMS, conversion to SPMS (defined, in agreement with previous studies, ${ }^{11,26,27}$ by development of irreversible EDSS score increase over at least a 1-year duration, independent of relapses) was also assessed.

\section{MRI Acquisition and Conventional MRI Analysis}

At baseline, the following MRI scans were collected using a 3.0T scanner from patients and $\mathrm{HC}$ (e-Methods, links.lww. com/NXI/A486): (1) T2*-weighted single-shot echo planar imaging for RS fMRI; (2) 3D T1-weighted fast field echo for T1-hypointense lesion volume (LV) and global brain volumetry assessment; and (3) dual-echo turbo spin echo for T2-hyperintense LV assessment.

\section{RS FC Within and Among Networks}

The main purpose was to use independent component (IC) analysis to produce RS FC networks. This was achieved, after RS fMRI preprocessing (e-Methods, links.lww.com/NXI/A486), using the GIFT software (mialab.mrn.org/software/gift/) and Infomax algorithm. The number of group ICs was 40, according to the minimum description length criterion. Visual inspection and template matching ${ }^{28-31}$ allowed selection of sensory, motor, and high-order integrative networks. The temporal association among selected ICs was explored using the functional network connectivity (FNC) toolbox (mialab.mrn.org, e-Methods, links. lww.com/NXI/A486). 
Figure 1 Main Functional and Structural Networks of Interest Related to Sensory, Motor, and High-Order Integrative Functions in Patients With Multiple Sclerosis (MS) and Healthy Controls (HCS)

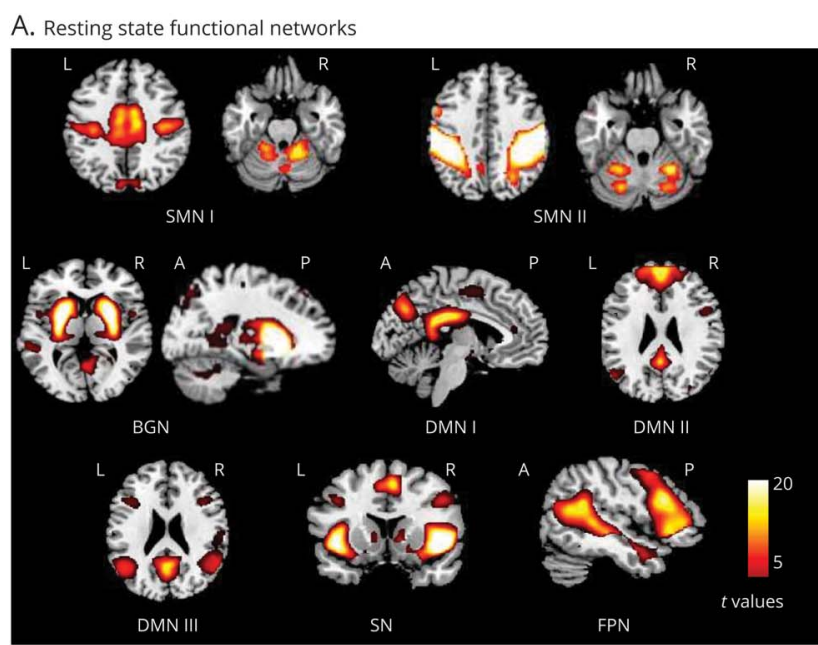

B. GM network

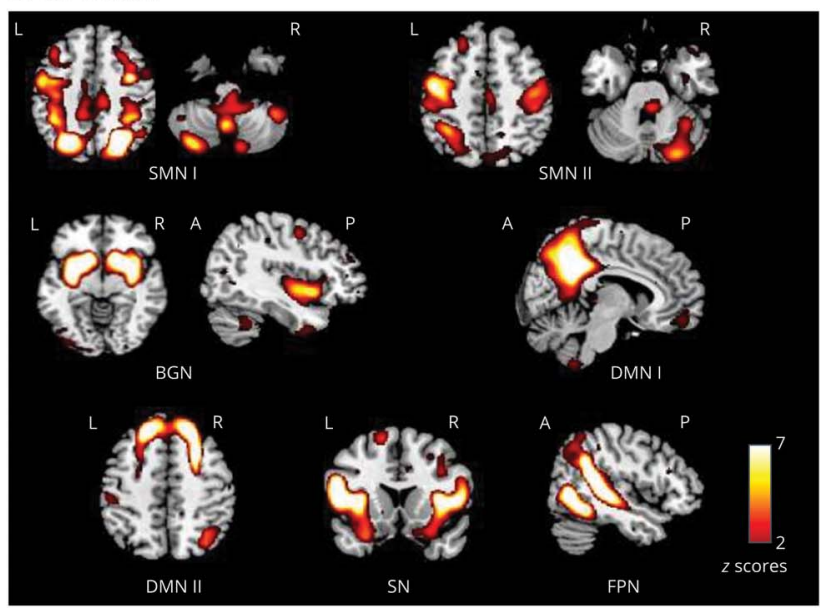

Spatial maps of relevant $(A)$ resting-state (RS) functional connectivity $(F C)$ and (B) gray matter (GM) networks. RS FC networks were thresholded at $p<$ 0.05 , with family-wise error corrected (positive effects of interest from the 2 sample $t$ test). GM structural networks were selected by visual inspection and spatial matching with RS FC networks, and as in previous studies, ${ }^{23}$ they were displayed using a threshold z-score $>2$.

\section{Structural GM Network Analysis: Source- Based Morphometry}

The main aim was to use source-based morphometry (SBM) to produce GM networks, that is, groups of distinct GM regions showing common covariations among subjects. Preprocessed GM maps (e-Methods, links.lww.com/NXI/A486) underwent the GIFT SBM toolbox and the Infomax algorithm. ${ }^{32}$ The SBM model order $(\mathrm{n}=40)$ matched functional analysis. After IC selection by visual inspection and spatial matching with functional components, ${ }^{33} \mathrm{GM}$ loading coefficients, representing the degree to which a network is present in individual subjects, were extracted and used for statistics. If the main sign was negative, GM IC maps and loading coefficients were inverted. ${ }^{32}$ Only pairs of matching functionalstructural networks were included.
Figure 2 Between-Group Comparison of Functional and Structural Networks Between HC and MS
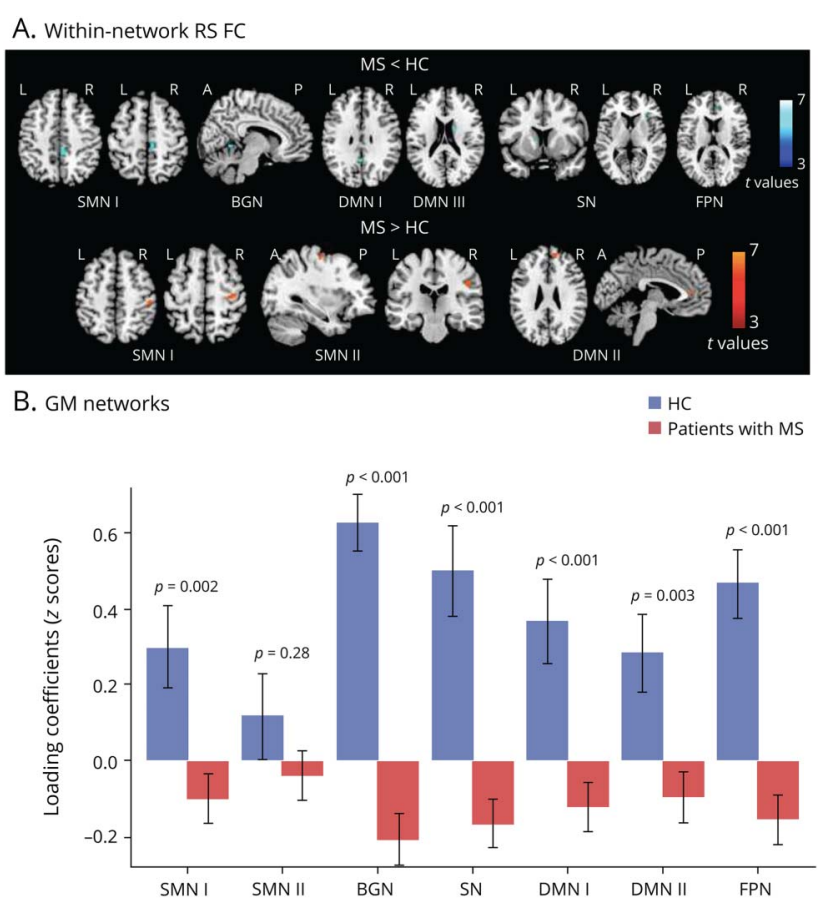

(A) Voxel-wise between-group comparisons of RS FC: the blue-light blue color scale shows decreased RS FC in MS vs HC, whereas the red-yellow color scale shows increased RS FC in MS vs HC (age- and sex-adjusted 2-sample $t$ test, $p<0.001$ uncorrected for illustrative purposes). (B) Boxplots showing average loading coefficients (means and SDs) of relevant GM networks. MS = multiple sclerosis; $\mathrm{FC}=$ functional connectivity; $\mathrm{GM}=$ gray matter; $\mathrm{HC}=$ healthy controls.

\section{Statistical Analysis}

\section{Between-Group Comparisons}

Analyses were performed using SAS (r.9.4) and R software (v.3.4.4). Normal distribution was checked with the Kolmogorov-Smirnov test, Shapiro-Wilk test, and Q-Q plots. LVs were log transformed. Between-group comparisons of demographic and clinical variables were assessed using the Pearson $\chi^{2}, 2$-sample $t$, or Mann-Whitney $U$ tests, as appropriate. Ageand sex-adjusted linear models were used to compare conventional MRI between groups. Patients with SPMS and those with PPMS were grouped together, leading to these comparisons: (1) patients with MS vs HCs; (2) patients with RRMS vs HCs; (3) patients with PMS vs HCs; and (4) patients with PMS vs RRMS.

Voxel-wise RS FC differences between patients with MS and HCs were investigated using SPM12 and age- and sex-adjusted linear models $(p<0.001$, uncorrected, and $p<0.05$, clusterwise family-wise error corrected). Models were masked with corrected effects of interest, retaining only significant RS FC within each network. Average RS FC Z-scores of regional significant difference were extracted using the MarsBaR toolbox.

\section{Prediction Analysis}

Follow-up duration-adjusted logistic regressions were run on all demographic, clinical, conventional, and network- 
Table 3 Candidate Predictors $(p<0.10)$ of Disability Worsening in All Patients With MS and Candidate Predictors of Conversion to SPMS in RRMS by Follow-up Adjusted Logistic Regression Models

\begin{tabular}{|c|c|c|c|c|c|c|c|c|}
\hline Predictors of disability worsening & $\begin{array}{l}\text { OR in all MS } \\
(95 \% \mathrm{Cl})\end{array}$ & SE & $p$ (unc) & $p$ (FDR) & $\begin{array}{l}\text { OR in RRMS } \\
(95 \% \mathrm{Cl})\end{array}$ & $\begin{array}{l}\text { OR in PMS } \\
(95 \% \mathrm{Cl})\end{array}$ & $p{\text { (unc })^{a}}^{a}$ & $p$ (FDR) \\
\hline Baseline age $^{b}$ & $1.83(1.39-2.41)$ & 0.36 & $<0.001$ & $<0.001$ & $1.84(1.26-2.69)$ & $1.03(0.62-1.7)$ & 0.07 & 0.52 \\
\hline Baseline $D^{b}$ & $1.69(1.20-2.38)$ & 0.23 & 0.003 & 0.01 & $1.43(0.87-2.36)$ & $0.95(0.53-1.7)$ & 0.30 & 0.73 \\
\hline Baseline EDSS score & $1.62(1.38-1.90)$ & 0.54 & $<0.001$ & $<0.001$ & $1.78(1.26-2.51)$ & $1.05(0.65-1.7)$ & 0.08 & 0.52 \\
\hline Baseline T2 LV & $2.29(1.34-3.89)$ & 0.24 & 0.002 & 0.01 & $1.57(0.75-3.28)$ & $0.89(0.3-2.64)$ & 0.40 & 0.87 \\
\hline Baseline T1 LV & $2.30(1.40-3.80)$ & 0.26 & 0.001 & 0.007 & $1.77(0.90-3.5)$ & $0.92(0.34-2.5)$ & 0.29 & 0.73 \\
\hline Baseline NBV & $0.53(0.40-0.7)$ & -0.38 & $<0.001$ & $<0.001$ & $0.50(0.34-0.72)$ & $1.0(0.60-1.68)$ & 0.03 & 0.52 \\
\hline Baseline NGMV & $0.38(0.26-0.56)$ & -0.42 & $<0.001$ & $<0.001$ & $0.37(0.22-0.62)$ & $0.80(0.39-1.6)$ & 0.08 & 0.52 \\
\hline Baseline NWMV ${ }^{c}$ & $0.57(0.34-0.10)$ & -0.15 & 0.05 & 0.13 & $0.41(0.18-0.94)$ & $1.56(0.59-4.14)$ & 0.04 & 0.52 \\
\hline Baseline NDGMV ${ }^{d}$ & $0.44(0.27-0.71)$ & -0.27 & $<0.001$ & 0.006 & $0.36(0.18-0.73)$ & $1.25(0.56-2.76)$ & 0.02 & 0.52 \\
\hline RS FC SMN I/R SMA & $0.72(0.55-1)$ & -0.15 & 0.05 & 0.13 & $0.77(0.53-1.13)$ & $0.65(0.37-1.17)$ & 0.64 & 0.92 \\
\hline RS FC SMN II - L Prec & $1.51(1.00-2.25)$ & 0.15 & 0.05 & 0.13 & $1.37(0.85-2.21)$ & $1.89(0.78-4.58)$ & 0.52 & 0.92 \\
\hline FNC DMN I-DMN III & $4.96(0.89-27.47)$ & 0.14 & 0.06 & 0.18 & $9.10(0.34-938.9)$ & $3.59(0.39-32.3)$ & 0.64 & 0.92 \\
\hline FNC DMN II-DMN III & $0.17(0.03-0.81)$ & -0.17 & 0.02 & 0.09 & $0.25(0.01-4.36)$ & $0.15(0.02-1.24)$ & 0.79 & 0.95 \\
\hline FNC DMN III-FPN & $2.36(1.05-5.32)$ & 0.15 & 0.03 & 0.12 & $6.34(0.93-43.0)$ & $1.66(0.60-4.58)$ & 0.22 & 0.71 \\
\hline GM SMN I & $0.62(0.47-0.83)$ & -0.26 & 0.001 & 0.007 & $0.58(0.40-0.85)$ & $0.88(0.49-1.58)$ & 0.25 & 0.71 \\
\hline GM SMN II & $0.71(0.54-0.94)$ & -0.19 & 0.02 & 0.06 & $0.70(0.48-1.0)$ & $0.85(0.53-1.37)$ & 0.51 & 0.92 \\
\hline GM BGN & $0.59(0.44-0.78)$ & -0.30 & $<0.001$ & 0.002 & $0.56(0.38-0.82)$ & $1.0(0.62-1.64)$ & 0.06 & 0.52 \\
\hline GM SN & $0.57(0.42-0.77)$ & -0.29 & $<0.001$ & $<0.001$ & $0.67(0.45-0.98)$ & $0.70(0.37-1.33)$ & 0.88 & 0.95 \\
\hline GM DMN I & $0.71(0.54-0.94)$ & -0.18 & 0.02 & 0.06 & $0.85(0.60-1.21)$ & $0.80(0.45-1.42)$ & 0.86 & 0.95 \\
\hline GM DMN II & $0.67(0.51-0.88)$ & -0.22 & 0.004 & 0.02 & $0.82(0.58-1.16)$ & $0.64(0.36-1.12)$ & 0.45 & 0.92 \\
\hline GM FPN & $0.72(0.55-0.94)$ & -0.19 & 0.01 & 0.06 & $0.71(0.50-1.01)$ & $1.03(0.60-1.75)$ & 0.26 & 0.71 \\
\hline Predictors of conversion to SPMS & \multicolumn{4}{|c|}{$\begin{array}{l}\text { OR for conversion to SPMS } \\
\text { in RRMS }(95 \% \mathrm{Cl})\end{array}$} & SE & \multicolumn{2}{|l|}{$p$ (unc) } & $p$ (FDR) \\
\hline Sex (male vs female) & \multicolumn{4}{|c|}{$3.28(1.34-8.03)$} & 0.32 & \multicolumn{2}{|l|}{0.009} & 0.08 \\
\hline Baseline age $^{\mathrm{b}}$ & \multicolumn{4}{|c|}{$2.17(1.32-3.57)$} & 0.42 & \multicolumn{2}{|l|}{0.002} & 0.02 \\
\hline Baseline EDSS score & \multicolumn{4}{|c|}{$3.22(2.05-5.07)$} & 0.65 & \multicolumn{2}{|l|}{$<0.001$} & $<0.001$ \\
\hline NBV ${ }^{c}$ & \multicolumn{4}{|c|}{$0.47(0.30-0.74)$} & -0.42 & \multicolumn{2}{|l|}{$<0.001$} & 0.01 \\
\hline$N^{N G M V^{c}}$ & \multicolumn{4}{|c|}{$0.33(0.18-0.61)$} & -0.46 & \multicolumn{2}{|l|}{$<0.001$} & 0.01 \\
\hline NDGMV $^{d}$ & \multicolumn{4}{|c|}{$0.48(0.21-1.11)$} & -0.21 & \multicolumn{2}{|l|}{0.09} & 0.35 \\
\hline RS FC SMN I - R SMA & \multicolumn{4}{|c|}{$0.63(0.39-1.04)$} & -0.23 & \multicolumn{2}{|l|}{0.07} & 0.35 \\
\hline FNC DMN II - BGN & \multicolumn{4}{|c|}{$3.52(0.86-14.3)$} & 0.23 & \multicolumn{2}{|l|}{0.07} & 0.35 \\
\hline FNC DMN II - DMN III & \multicolumn{4}{|c|}{$0.08(0.009-0.88)$} & -0.22 & \multicolumn{2}{|l|}{0.04} & 0.24 \\
\hline GM SMN I & \multicolumn{4}{|c|}{$0.41(0.24-0.70)$} & -0.51 & \multicolumn{2}{|l|}{0.001} & 0.01 \\
\hline GM SMN II & \multicolumn{4}{|c|}{$0.42(0.25-0.70)$} & -0.46 & \multicolumn{2}{|l|}{$<0.001$} & 0.01 \\
\hline GM BGN & \multicolumn{4}{|c|}{$0.66(0.42-1.04)$} & -0.21 & \multicolumn{2}{|l|}{0.07} & 0.35 \\
\hline
\end{tabular}


Table 3 Candidate Predictors $(p<0.10$ ) of Disability Worsening in All Patients With MS and Candidate Predictors of Conversion to SPMS in RRMS by Follow-up Adjusted Logistic Regression Models (continued)

\begin{tabular}{|c|c|c|c|c|}
\hline Predictors of conversion to SPMS & $\begin{array}{l}\text { OR for conversion to SPMS } \\
\text { in RRMS }(95 \% \mathrm{CI})\end{array}$ & SE & $p$ (unc) & $p$ (FDR) \\
\hline GM DMN I & $0.66(0.41-1.05)$ & -0.23 & 0.08 & 0.35 \\
\hline GM FPN & $0.57(0.36-0.92)$ & -0.32 & 0.02 & 0.12 \\
\hline \multicolumn{5}{|c|}{ 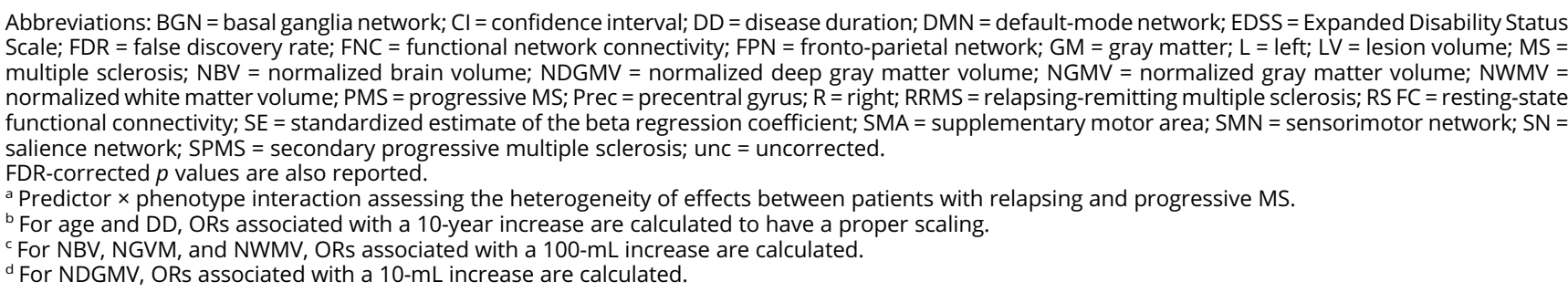 } \\
\hline
\end{tabular}

based MRI variables assessed in this study $(\mathrm{n}=62$, listed in e-table 1, links.lww.com/NXI/A485) to determine candidate predictors $(p<0.1)^{9,10,34}$ of disability worsening and conversion to SPMS to be further considered for random forest (RF) analysis. The heterogeneity of between-phenotype effects was tested with interaction terms. Then, RF probability models were used to identify variables independently associated with clinical worsening and SPMS conversion. For each model, 10,000 trees were built on a random subset of covariates (including only demographic and clinical variables, adding conventional and finally network MRI variables), with a follow-up duration-weighted bootstrap resampling of observations. We assessed feature relevance with an outcome permutation test (1,000 permutations), providing an unbiased measure of variable importance and significance $p$ values for each predictor. ${ }^{35}$ DMT change, but not DMT at baseline, was included as a covariate because it did not differ between stable/worsened MS, nor between SPMS converters/nonconverters. We reported the out-of-bag (OOB) Brier score (mean squared prediction error) of final models, based on selected features. A receiver operating characteristic analysis tested the significance of partial contributions of conventional and network MRI vs clinical variables to model discriminative ability (OOB area under the curve $[\mathrm{AUC}]$ ).

Considering the exploratory nature of our analysis, significance in logistic regression and RF analyses was set at $p<0.1$, false discovery rate (FDR) corrected for multiple comparisons (Benjamini-Hochberg procedure). Uncorrected results $(p<$ $0.05)$ are also reported.

\section{Data Availability}

The data set used and analyzed during the current study is available from the corresponding author on reasonable request.

\section{Results}

\section{Demographic, Clinical, and Conventional MRI}

Compared with HCs, patients with MS (as a whole and according to phenotype) showed significantly lower brain and deep GM volumetry. Patients with PMS were older $(p<$
0.001), had higher EDSS score $(p<0.001)$, longer disease duration $(p<0.001)$, higher T2 $(p<0.001)$ and T1 LV $(p<$ $0.001)$, and lower brain volumetry ( $p=$ range $<0.001-0.002)$ than those with RRMS (table 1).

The median EDSS score at follow-up was $=4.0$ (interquartile range $=1.5-6.5)$ (median EDSS score change between baseline and follow-up $=0.5$, interquartile range $=0.0-1.5, p$ value vs baseline $<0.0001)$. According to EDSS score changes, 105 patients with MS (45\%) were clinically worsened at follow-up: 1 patient (of 2, 50\%) had baseline EDSS score $=0$, 71 patients (of 184, 38\%) had baseline EDSS score between 0.5 and 5.5 , and 33 patients (of $47,70 \%$ ) had baseline EDSS score $\geq 6$. Moreover, 26 patients with RRMS (16\%) converted to SPMS.

At baseline, compared with clinically stable, patients with clinically worsened MS were older, had longer disease duration, higher EDSS score, higher LV, and more severe wholebrain and GM atrophy (table 2). Compared with patients remaining RRMS, SPMS converters had a higher proportion of males, were older, and had higher baseline EDSS score and lower brain volumetry (table 2).

\section{RS FC Networks}

Eight functional networks (figure 1) were selected: 2 sensorimotor networks (SMN I and II), ${ }^{28} 1$ basal ganglia network (BGN), ${ }^{29} 3$ default-mode networks (DMNs I, II, and III),$^{30} 1$ salience network $(\mathrm{SN}){ }^{31}$ and 1 fronto-parietal network (FPN) associated with working memory and dorsal atten$\operatorname{tion}^{28}$ ( $\mathrm{r}$ with corresponding templates $=$ range $\left.0.40-0.65\right)$.

At the regional level, decreased and increased RS FC within specific regions in patients with MS vs $\mathrm{HC}$ were found (etable 2, links.lww.com/NXI/A485; figure 2). Specifically, decreased RS FC was observed in patients with MS within the SMN I in the right paracentral lobule and supplementary motor area (SMA), within the BGN in the right cerebellum, within the SN in the right insula and left caudate nucleus, within the DMN I/III in the left posterior cingulate and right 
Table 4 Informative Predictors of Disability Worsening in All Patients With MS, as Well as Independent Predictors of Conversion to SPMS in RRMS, Selected by Random Forest Analyses

\begin{tabular}{|c|c|c|c|c|c|c|}
\hline Predictors of disability worsening & Relative importance & $\begin{array}{l}p \\
\text { Value }\end{array}$ & $\begin{array}{l}p \text { (FDR } \\
\text { corrected) }\end{array}$ & $\begin{array}{l}\text { OOB-Brier } \\
\text { score }\end{array}$ & $\begin{array}{l}\text { OOB-AUC (95\% } \\
\text { CI) }\end{array}$ & $\begin{array}{l}p \\
\text { Value }\end{array}$ \\
\hline \multicolumn{7}{|l|}{ Clinical variables } \\
\hline Baseline EDSS score & 100.0 & 0.001 & 0.003 & 0.227 & $0.68(0.61-0.75)$ & - \\
\hline DMT change & 21.7 & 0.03 & 0.05 & & & \\
\hline
\end{tabular}

\section{Clinical and conventional MRI}

variables

\begin{tabular}{|c|c|c|c|c|c|c|c|}
\hline Baseline EDSS score & 100.0 & & 0.001 & 0.004 & 0.223 & $0.71(0.64-0.77)$ & $0.38^{\mathrm{a}}$ \\
\hline NGMV & 61.8 & & 0.001 & 0.004 & & & \\
\hline NBV & 37.1 & & 0.01 & 0.03 & & & \\
\hline \multirow[t]{2}{*}{ DMT change } & 18.3 & & 0.01 & 0.03 & & & \\
\hline & $\begin{array}{l}\text { Clinica } \\
\text { variabl }\end{array}$ & entional, and network MRI & & & & & \\
\hline Baseline EDSS score & 100.0 & & 0.001 & 0.01 & 0.199 & $0.76(0.69-0.82)$ & $0.009^{a}$ \\
\hline NGMV & 73.5 & & 0.001 & 0.01 & & & \\
\hline NBV & 35.7 & & 0.005 & 0.03 & & & \\
\hline FNC DMN II-DMN III & 23.9 & & 0.03 & 0.09 & & & \\
\hline RS FC SMN II - L precentral gyrus & 18.9 & & 0.03 & 0.09 & & & \\
\hline GM FPN & 18.2 & & 0.03 & 0.09 & & & \\
\hline GM SMN II & 16.8 & & 0.04 & 0.11 & & & \\
\hline GM SN & 15.4 & & 0.04 & 0.11 & & & \\
\hline DMT change & 7.9 & & 0.01 & 0.08 & & & \\
\hline Predictors of conversion to SPMS & & $\begin{array}{l}\text { Relative } \\
\text { importance }\end{array}$ & $p($ FDR & R corrected) & $\begin{array}{l}\text { OOB-Brier } \\
\text { score }\end{array}$ & OOB-AUC ( $95 \% \mathrm{Cl})$ & $p$ Value \\
\hline \multicolumn{8}{|l|}{ Clinical variables } \\
\hline Baseline EDSS score & & 0.001 & 0.03 & & 0.120 & $0.75(0.66-0.85)$ & - \\
\hline DMT change & & 18.9 & 0.09 & & & & \\
\hline \multicolumn{8}{|c|}{ Clinical and conventional MRI variables } \\
\hline NGMV & & 0.004 & 0.009 & & 0.104 & $0.83(0.73-0.92)$ & $0.09^{a}$ \\
\hline Baseline EDSS score & & 0.001 & 0.006 & & & & \\
\hline DMT change & & 0.003 & 0.009 & & & & \\
\hline \multicolumn{8}{|c|}{ Clinical, conventional and network MRI variables } \\
\hline Baseline EDSS score & & $<0.001$ & 0.01 & & 0.111 & $0.84(0.76-0.91)$ & $0.02^{\mathrm{a}}$ \\
\hline NGMV & & 0.001 & 0.01 & & & & \\
\hline GM SMN I & & 0.03 & 0.09 & & & & \\
\hline DMT change & & 0.002 & 0.01 & & & & \\
\hline
\end{tabular}

Abbreviations: $\mathrm{AUC}=$ area under the curve; $\mathrm{Cl}=$ confidence interval; $\mathrm{DMN}=$ default-mode network; $\mathrm{DMT}=$ disease-modifying treatment; $\mathrm{EDSS}=\mathrm{Expanded}$ Disability Status Scale; FDR = false discovery rate; FNC = functional network connectivity; FPN = fronto-parietal network; GM = gray matter; $L=$ left; $M S=$ multiple sclerosis; NBV = normalized brain volume; NGMV = normalized gray matter volume; $\mathrm{OOB}$ = out of bag; RRMS = relapsing-remitting multiple sclerosis; RS FC = resting-state functional connectivity; SMN = sensorimotor network; SN = salience network; SPMS = secondary progressive multiple sclerosis. Out-of-bag (OOB) area under the curve (AUC) values and related $p$ values highlight the performance increase associated with the inclusion of conventional and network MRI variables, compared with models including confounding covariates and clinical variables.

${ }^{a}$ Compared with the model including clinical variables. 
Figure 3 Analysis of Prediction

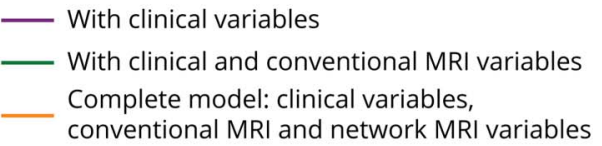

A. Clinical disability worsening

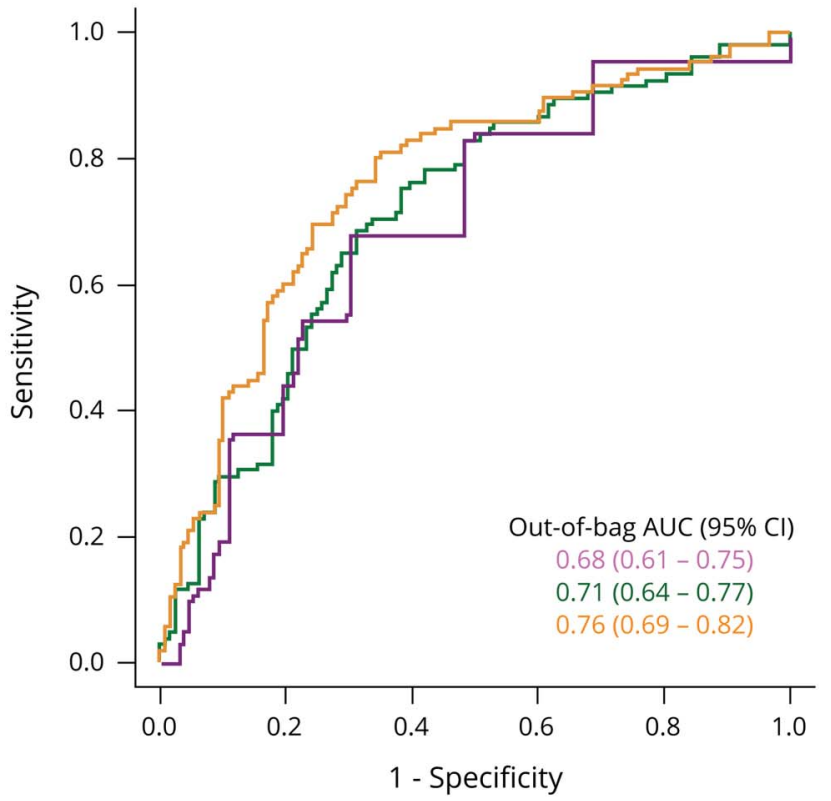

B. Conversion to SPMS

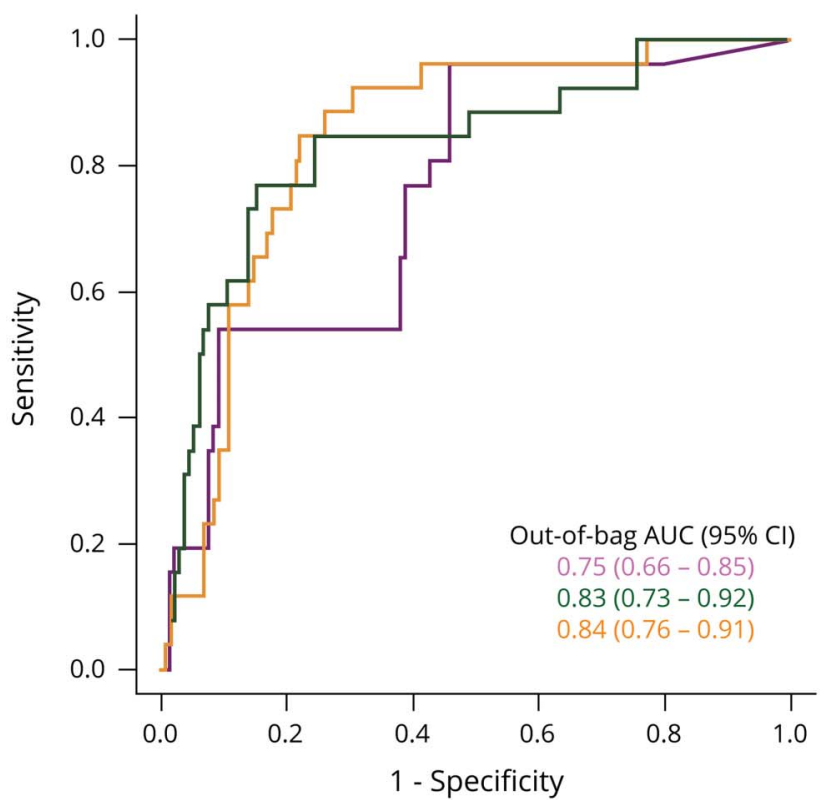

Results of the ROC analysis showing the area under the curve (OOB AUC) of random forest models predicting clinical disability worsening $(A)$ and conversion to SPMS (B). Models show the increments of AUC associated with the inclusion of conventional MRI variables (green lines) and network MRI variables (orange lines) in addition to confounding covariates and clinical variables (purple lines). AUC = area under the curve; OOB = out-of-bag; ROC = receiver operating characteristic; SPMS = secondary progressive multiple sclerosis.

caudate nucleus, and within the FPN in the right anterior cingulate. Increased RS FC was detected in the bilateral precentral and postcentral gyrus within the SMN I/II, and frontal regions within the DMN II.

Considering FNC analysis, connectivity strength was significantly decreased in patients with MS vs HCs between SMN I-BGN $(p=0.02)$ and SMN I-DMN II $(p=0.01)$, as well as between FPN-DMN I $(p=0.01)$ and FPN-SN $(p=0.002)$ (etable 2, links.lww.com/NXI/A485).

\section{GM Networks}

Seven GM networks matched functional networks: 2 SMNs, one including precentral and postcentral, middle occipital gyri, and cerebellum ( $\mathrm{r}$ with functional SMN I $=0.32, p<0.001$ ) and the other including precentral gyri, SMA, and cerebellum ( $\mathrm{r}$ with functional SMN II $=0.44, p<0.001$ ); 1 BGN, including deep GM and cerebellum ( $\mathrm{r}$ with functional BGN $=0.80, p<$ $0.001) ; 2 \mathrm{DMNs}$, one including posterior cingulate, precuneus, and angular gyri ( $\mathrm{r}$ with functional DMN I $=0.55, p<0.001$ ) and the other including medial frontal, middle frontal, and angular gyri ( $\mathrm{r}$ with functional DMN II $=0.73, p<0.001) ; 1 \mathrm{SN}$ ( $\mathrm{r}$ with functional SN $=0.56, p<0.001$ ); and $1 \mathrm{FPN}$ ( $\mathrm{r}$ with functional FPN $=0.43, p<0.001) .{ }^{33}$ Patients with MS showed significant GM atrophy (i.e., lower GM loadings) vs HCs in all networks, except for SMN II (figure 2).

\section{Prediction Analysis}

The univariate analysis identified, at corrected threshold, older baseline age, longer disease duration, higher EDSS score, higher LV, lower global brain volumetry, lower GM loading coefficients for all networks, and reduced FNC between DMN II-DMN III as candidate predictors of disability worsening (table 3). At an uncorrected threshold, the following candidate predictors of EDSS score worsening were also identified: decreased RS FC in the SMA and increased RS FC in the left precentral gyrus of SMNs, reduced FNC between DMN III-FPN, and increased FNC between DMN I-DMN III (table 3).

RF analysis identified as FDR-corrected predictors of clinical worsening a higher baseline EDSS score, lower normalized brain and GM volumes, reduced FNC between DMN IIDMN III, increased RS FC of the left precentral gyrus (SMN II), and GM atrophy in FPN (table 4, figure 3). An FDRuncorrected contribution of GM atrophy in SMN II and SN was also found. When considering all predictors, the receiver operating characteristic analysis (AUC $=0.76$, table 4 , figure 3 ) highlighted that the inclusion of network MRI variables significantly improved $(p=0.009)$ prediction performances. Results did not change substantially with FDR-corrected predictors only (AUC $=0.74$, improvement of prediction performance: $p=0.05)$.

The univariate analysis identified as FDR-corrected predictors for SPMS conversion male sex, older baseline age, higher EDSS score, lower normalized brain and GM volumes, and GM loadings of SMN and FPN (table 3). At an uncorrected 
threshold, the following candidate SPMS predictors were also detected: lower deep GM volumes, decreased RS FC in the SMA (SMN I), decreased FNC between DMN II-DMN III and DMN II-BGN, and lower GM loadings of BGN and DMN (table 3). As shown in table 4, the RF model selected baseline EDSS score, normalized GM volume, and GM atrophy in the SMN I as FDR-corrected predictors of SPMS conversion. The receiver operating characteristic analysis (table 4, figure 3) highlighted the significant contribution ( $p=$ 0.02 ) of network MRI variables to model performance.

\section{Discussion}

By analyzing a large cohort of patients with MS having a 6.4year follow-up clinical evaluation, we found that integrating structural and functional network measures significantly improved clinical worsening prediction. Besides higher baseline EDSS score and lower whole-GM volumetry, abnormal baseline RS FC within and between sensorimotor and DMNs, as well as sensorimotor and cognitive GM network atrophy, contributed to explain overall disability progression. Moreover, GM atrophy in an SMN was among the determinants of SPMS conversion. Prediction models of both clinical worsening and SPMS conversion were produced using RF methodology, a machine-learning technique that is less sensitive to false discoveries than classic multivariate logistic models, ${ }^{36}$ being based on the use of different bootstrap samples of data and different subsets of predictors to construct thousands of decision trees, on which hypotheses are tested. ${ }^{36}$

As clinical outcomes, we selected the EDSS score, the most widely validated MS disability measure, which was used in all prognostic studies, ${ }^{6,7,9-12,14,15}$ and evolution to SPMS, that is associated with a poor prognosis, mostly because of the limited DMT effect in these patients. During the 6.4-year followup, $45 \%$ of patients had a worsening of disability and $16 \%$ of patients with RRMS evolved to SPMS. In line with previous studies, older age, longer disease duration, and higher baseline EDSS score were associated with poorer clinical outcomes. ${ }^{7,37}$ In particular, a higher baseline EDSS score was retained by multivariable analysis as a predictor of both worsening of disability and evolution to SPMS. This is in line with a recent meta-analysis, indicating baseline EDSS score as the most frequent predictor of future disease course. ${ }^{7}$ On the other hand, this result may be partially driven by autocorrelation issues.

In addition to baseline disability, different MRI measures contributed to the prediction of disease evolution. Concerning conventional MRI, whole-brain atrophy was predictive of disease worsening at RF analysis. Likewise, whole-GM atrophy was retained as a predictor of both clinical worsening and SPMS conversion. The notion that whole-GM atrophy is one of the most important MRI measures explaining disability deterioration is in line with previous medium- and long-term studies. ${ }^{9,11,12}$ Because we included both RRMS and PMS, our results support the importance of this measure independently from phenotype and reinforce the notion that the neurodegenerative MS-related damage is more critical than inflammation to explain a worse clinical course. In line with this, $\mathrm{LV}$ was not retained as a predictor by any RF model.

One of the main strengths of this study, compared with previous ones, was the assessment of network-specific MRI measures. This was a rewarding strategy to ameliorate prediction of MS disease evolution because both functional and structural network MRI abnormalities were found to be informative of subsequent clinical deterioration at mediumterm, and inclusion of network MRI metrics in RF models significantly improved prediction performance.

Considering the prediction of EDSS score worsening, $2 \mathrm{fMRI}$ outcomes were selected by RF analysis, namely, decreased FNC among DMNs and increased RS FC of the left precentral gyrus in the SMN II. The role of fMRI for prognosis has still to be fully investigated. Although there is some preliminary evidence of a significant influence of baseline FC during a psychological stress fMRI task on subsequent development of atrophy, ${ }^{21}$ and a significant influence of baseline RS FC abnormalities on subsequent clinical disability, ${ }^{19,20}$ studies in large patients' groups including all main disease phenotypes are still missing. Here, a prevalent decrease of RS FC among networks ${ }^{18}$ and a heterogeneous pattern of regionally increased and decreased RS FC were confirmed. ${ }^{18,23,38}$ However, only abnormalities of RS FC in the DMN and SMN were associated with EDSS score worsening. The DMN is one of the key networks of the brain, and abnormal DMN RS FC is present in several brain disorders, including MS. ${ }^{23,30}$ A good control of DMN activity is crucial for an efficient brain function. ${ }^{30}$ In line with this, we found that reduced RS FC between 2 DMN patterns (including the posterior and the anterior nodes of this network, respectively) was able to explain clinical worsening. This reinforces the notion of a close correlation between impaired functional communication and increasing disability in MS. On the other hand, we also found that a selective increase of RS FC within a specific region of the SMN (i.e., the left precentral gyrus) was predictive of clinical deterioration. A previous 2-year graph analysis study in 38 patients with early RRMS $^{20}$ showed that at baseline, patients had an increased network RS FC, which tended to decrease during the study follow-up, concomitantly with disability progression. Previous findings suggest that increased RS FC may occur at early disease stages to compensate structural damage and may stop after reaching a maximum level. ${ }^{19,20,39}$ In later phases, RS FC depletion is thought to contribute to disability progression. ${ }^{20,23}$ Our results further support such hypothesis in a larger group of patients and with a longer follow-up. Remarkably, we found that this behavior distinguished the SMN, which is most likely clinically related to EDSS score deterioration.

Of interest, besides whole-GM atrophy, RF analysis also identified GM atrophy in the FPN to be predictive of a worse disease evolution. This is not the first study that highlights a significant contribution of network GM measures to MS 
prognosis. ${ }^{14,15}$ Taken together, these results suggest that the assessment of specific system involvement may convey more clinically relevant pieces of information than global MRI measures in these patients.

In patients with RRMS, RF analysis identified atrophy of SMN I as significantly contributing to explain evolution to SPMS, whereas none of the other advanced MRI measures significant at the univariate analysis was retained. A unique definition of SPMS is still lacking and is a matter of current research. ${ }^{40}$ To be consistent with available literature, we applied the definition used in integrated clinical-MRI prognostic studies. ${ }^{911,26}$ The relation that we found between SMN atrophy and evolution to SPMS is not unexpected, considering that disability worsening in these patients is mostly driven by a progressive impairment of ambulation. In line with this, previous cross-sectional studies found peculiar atrophy of brain motor areas in patients with SPMS. ${ }^{41}$

Our study has the unique value of a large, monocentric, wellcharacterized patients' cohort. However, this study has some limitations. First, clinical evaluation did not include a baseline and follow-up cognitive assessment, which can have detrimental consequences on patients' functioning. Moreover, because we did not have a cognitive evaluation, we could not assess worsening of other scores than EDSS (e.g., the Multiple Sclerosis Functional Composite). Second, because of the complexity of the MRI protocol, we did not include a spinal cord evaluation, which may be relevant for disability accumulation and SPMS evolution. ${ }^{11}$ Third, a follow-up MRI scan was not available, thus making it impossible to quantify changes of WM LV and/or other MRI disease severity parameters. Fourth, not all data-driven structural and functional networks had a significant spatial correspondence, leading to the exclusion of potentially interesting components (e.g., the visual network); moreover, they may be not fully replicable in different data sets. Fifth, given the exploratory nature of this study, we used a relatively liberal threshold for FDR correction; moreover, the small portion of results not surviving at this threshold should be interpreted with extreme caution. Sixth, the use of the whole data set for feature selection (with logistic regressions) and for the subsequent construction of RF models may increase the risk of model overfitting; as such, results may be biased by double-dipping issues. Finally, this study was not planned to assess the role of treatment on clinical outcomes. Therefore, detailed information on treatment exposure was not collected and analyzed.

To conclude, we found that integrating structural and functional MRI network measures improved prediction of clinical worsening. The added value of other MRI and serologic biomarkers, such as WM network damage assessed by diffusion-weighted MRI, demyelination/remyelination indices derived from magnetization transfer imaging, or neurofilament light chain, might be the topic of future investigations.

\section{Study Funding}

This study was partially supported by FISM (Fondazione Italiana Sclerosi Multipla) cod. 2018/R/5 and was financed or co-financed with the " 5 per mille" public funding.

\section{Disclosure}

M.A. Rocca received speaker honoraria from Bayer, Biogen, Bristol-Myers Squibb, Celgene, Genzyme, Merck-Serono, Novartis, Roche, and Teva and receives research support from the Italian Ministry of Health, MS Society of Canada, and Fondazione Italiana Sclerosi Multipla. P Valsasina, A Meani, and E Pagani received speaker's honoraria from Biogen Idec. C. Cordani and C. Cervellin report no disclosures relevant to the manuscript. M Filippi is Editor-in-Chief of the Journal of Neurology and Associate Editor of Human Brain Mapping; received compensation for consulting services and/or speaking activities from Almirall, Alexion, Bayer, Biogen, Celgene, Eli Lilly, Genzyme, Merck-Serono, Novartis, Roche, Sanofi, Takeda, and Teva Pharmaceutical Industries; and receives research support from Biogen Idec, Merck-Serono, Novartis, Roche, Teva Pharmaceutical Industries, Italian Ministry of Health, Fondazione Italiana Sclerosi Multipla, and ARiSLA (Fondazione Italiana di Ricerca per la SLA). Go to Neurology.org/NN for full disclosures.

\section{Publication History}

Received by Neurology: Neuroimmunology of Neuroinflammation August 26, 2020. Accepted in final form March 5, 2021.

\begin{tabular}{|c|c|c|}
\hline Name & Location & Contribution \\
\hline $\begin{array}{l}\text { Maria A. } \\
\text { Rocca, MD }\end{array}$ & $\begin{array}{l}\text { IRCCS San Raffaele Scientific } \\
\text { Institute, Milan, Italy; Vita- } \\
\text { Salute San Raffaele } \\
\text { University, Milan, Italy }\end{array}$ & $\begin{array}{l}\text { Study concept, analysis and } \\
\text { interpretation of the data, } \\
\text { and drafting/revising the } \\
\text { manuscript }\end{array}$ \\
\hline $\begin{array}{l}\text { Paola } \\
\text { Valsasina, } \\
\text { MSc }\end{array}$ & $\begin{array}{l}\text { IRCCS San Raffaele Scientific } \\
\text { Institute, Milan, Italy }\end{array}$ & $\begin{array}{l}\text { Analysis and interpretation of } \\
\text { the data and drafting/revising } \\
\text { the manuscript }\end{array}$ \\
\hline $\begin{array}{l}\text { Alessandro } \\
\text { Meani, MsC }\end{array}$ & $\begin{array}{l}\text { IRCCS San Raffaele Scientific } \\
\text { Institute, Milan, Italy }\end{array}$ & $\begin{array}{l}\text { Analysis and interpretation of } \\
\text { the data and drafting/revising } \\
\text { the manuscript }\end{array}$ \\
\hline $\begin{array}{l}\text { Elisabetta } \\
\text { Pagani, } \\
\text { MSc }\end{array}$ & $\begin{array}{l}\text { IRCCS San Raffaele Scientific } \\
\text { Institute, Milan, Italy }\end{array}$ & $\begin{array}{l}\text { Analysis and interpretation of } \\
\text { the data and drafting/revising } \\
\text { the manuscript }\end{array}$ \\
\hline $\begin{array}{l}\text { Claudio } \\
\text { Cordani, PT }\end{array}$ & $\begin{array}{l}\text { IRCCS San Raffaele Scientific } \\
\text { Institute, Milan, Italy }\end{array}$ & $\begin{array}{l}\text { Acquisition of the data and } \\
\text { analysis and interpretation of } \\
\text { the data }\end{array}$ \\
\hline $\begin{array}{l}\text { Chiara } \\
\text { Cervellin, } \\
\text { PT }\end{array}$ & $\begin{array}{l}\text { IRCCS San Raffaele Scientific } \\
\text { Institute, Milan, Italy }\end{array}$ & $\begin{array}{l}\text { Acquisition of the data and } \\
\text { analysis and interpretation of } \\
\text { the data }\end{array}$ \\
\hline $\begin{array}{l}\text { Massimo } \\
\text { Filippi, MD }\end{array}$ & $\begin{array}{l}\text { IRCCS San Raffaele Scientific } \\
\text { Institute, Vita-Salute San } \\
\text { Raffaele University, Milan, } \\
\text { Italy }\end{array}$ & $\begin{array}{l}\text { Drafting/revising the } \\
\text { manuscript, study concept, } \\
\text { and analysis and } \\
\text { interpretation of the data. He } \\
\text { also acted as the study } \\
\text { supervisor. }\end{array}$ \\
\hline
\end{tabular}




\section{References}

1. Filippi M, Bar-Or A, Piehl F, et al. Multiple sclerosis. Nat Rev Dis Primers 2018;4:43.

2. Montalban X, Gold R, Thompson AJ, et al. ECTRIMS/EAN Guideline on the pharmacological treatment of people with multiple sclerosis. Mult Scler 2018;24: 96-120.

3. Thompson AJ, Banwell BL, Barkhof F, et al. Diagnosis of multiple sclerosis: 2017 revisions of the McDonald criteria. Lancet Neurol 2018;17:162-173.

4. Gasperini C, Prosperini L, Tintore M, et al. Unraveling treatment response in multiple sclerosis: a clinical and MRI challenge. Neurology 2019;92:180-192.

5. Fisniku LK, Brex PA, Altmann DR, et al. Disability and T2 MRI lesions: a 20-year follow-up of patients with relapse onset of multiple sclerosis. Brain 2008;131: 808-817.

6. Elliott C, Belachew S, Wolinsky JS, et al. Chronic white matter lesion activity predicts clinical progression in primary progressive multiple sclerosis. Brain 2019;142: 2787-2799.

7. Brown FS, Glasmacher SA, Kearns PKA, et al. Systematic review of prediction models in relapsing remitting multiple sclerosis. PLoS One 2020;15:e0233575.

8. Enzinger C, Barkhof F, Ciccarelli O, et al. Nonconventional MRI and microstructural cerebral changes in multiple sclerosis. Nat Rev Neurol 2015;11:676-686.

9. Filippi M, Preziosa P, Copetti M, et al. Gray matter damage predicts the accumulation of disability 13 years later. Neurology 2013;81:1759-1767.

10. Rocca MA, Sormani MP, Rovaris M, et al. Long-term disability progression in primary progressive multiple sclerosis: a 15-year study. Brain 2017;140:2814-2819.

11. Brownlee WJ, Altmann DR, Prados F, et al. Early imaging predictors of long-term outcomes in relapse-onset multiple sclerosis. Brain 2019;142:2276-2287.

12. Dekker I, Eijlers AJC, Popescu V, et al. Predicting clinical progression in multiple sclerosis after 6 and 12 years. Eur J Neurol 2019;26:893-902.

13. He Y, Dagher A, Chen Z, et al. Impaired small-world efficiency in structural cortical networks in multiple sclerosis associated with white matter lesion load. Brain 2009; 132:3366-3379.

14. Muthuraman M, Fleischer V, Kroth J, et al. Covarying patterns of white matter lesions and cortical atrophy predict progression in early MS. Neurol Neuroimmunol Neuroinflamm 2020;7:e681.

15. Tur C, Kanber B, Eshaghi A, et al. Clinical relevance of cortical network dynamics in early primary progressive MS. Mult Scler 2020;26:442-456.

16. Rocca MA, Valsasina P, Meani A, Falini A, Comi G, Filippi M. Impaired functional integration in multiple sclerosis: a graph theory study. Brain Struct Funct 2016;221. $115-131$.

17. Liu Y, Duan Y, Dong H, Barkhof F, Li K, Shu N. Disrupted module efficiency of structural and functional brain connectomes in clinically isolated syndrome and multiple sclerosis. Front Hum Neurosci 2018;12:138.

18. Rocca MA, Valsasina P, Martinelli V, et al. Large-scale neuronal network dysfunction in relapsing-remitting multiple sclerosis. Neurology 2012;79:1449-1457.

19. Hidalgo de La Cruz M, Valsasina P, Mesaros S, et al. Clinical predictivity of thalamic sub-regional connectivity in clinically isolated syndrome: a 7-year study. Mol Psychiatry 2020.

20. Faivre A, Robinet E, Guye M, et al. Depletion of brain functional connectivity enhancement leads to disability progression in multiple sclerosis: a longitudinal restingstate fMRI study. Mult Scler 2016;22:1695-1708.
21. Meyer-Arndt L, Hetzer S, Asseyer S, et al. Blunted neural and psychological stress processing predicts future grey matter atrophy in multiple sclerosis. Neurobiol Stress 2020;13:100244.

22. Lublin FD, Reingold SC, Cohen JA, et al. Defining the clinical course of multiple sclerosis: the 2013 revisions. Neurology 2014;83:278-286.

23. Rocca MA, Valsasina P, Leavitt VM, et al. Functional network connectivity abnormalities in multiple sclerosis: correlations with disability and cognitive impairment. Mult Scler 2018;24:459-471.

24. Kurtzke JF. Rating neurologic impairment in multiple sclerosis: an expanded disability status scale (EDSS). Neurology 1983;33:1444-1452.

25. Healy BC, Engler D, Glanz B, Musallam A, Chitnis T. Assessment of definitions of sustained disease progression in relapsing-remitting multiple sclerosis. Mult Scler Int 2013;2013:189624.

26. University of California SFMSET, Cree BA, Gourraud PA, Oksenberg JR, et al. Long-term evolution of multiple sclerosis disability in the treatment era. Ann Neurol 2016;80:499-510.

27. Scalfari A, Neuhaus A, Daumer M, Deluca GC, Muraro PA, Ebers GC. Early relapses, onset of progression, and late outcome in multiple sclerosis. JAMA Neurol 2013;70:214-222.

28. Smith SM, Fox PT, Miller KL, et al. Correspondence of the brain's functional architecture during activation and rest. Proc Natl Acad Sci United States America 2009. 106:13040-13045.

29. Patenaude B, Smith SM, Kennedy DN, Jenkinson M. A Bayesian model of shape and appearance for subcortical brain segmentation. NeuroImage 2011;56:907-922.

30. Raichle ME, Snyder AZ. A default mode of brain function: a brief history of an evolving idea. NeuroImage 2007;37:1083-1090. discussion 1097-1089.

31. Seeley WW, Menon V, Schatzberg AF, et al. Dissociable intrinsic connectivity networks for salience processing and executive control. J Neurosci 2007;27:2349-2356.

32. Xu L, Groth KM, Pearlson G, Schretlen DJ, Calhoun VD. Source-based morphom etry: the use of independent component analysis to identify gray matter differences with application to schizophrenia. Hum Brain Mapp 2009;30:711-724.

33. Segall JM, Allen EA, Jung RE, et al. Correspondence between structure and function in the human brain at rest. Front neuroinformatics 2012;6:10

34. Rocca MA, Parisi L, Pagani E, et al. Regional but not global brain damage contributes to fatigue in multiple sclerosis. Radiology 2014;273:511-520.

35. Altmann A, Tolosi L, Sander O, Lengauer T. Permutation importance: a corrected feature importance measure. Bioinformatics 2010;26:1340-1347.

36. Kacar K, Rocca MA, Copetti M, et al. Overcoming the clinical-MR imaging paradox of multiple sclerosis: MR imaging data assessed with a random forest approach. AJNR Am J Neuroradiol 2011;32:2098-2102.

37. Fambiatos A, Jokubaitis V, Horakova D, et al. Risk of secondary progressive multiple sclerosis: a longitudinal study. Mult Scler 2020;26:79-90.

38. Faivre A, Rico A, Zaaraoui W, et al. Assessing brain connectivity at rest is clinically relevant in early multiple sclerosis. Mult Scler 2012;18:1251-1258.

39. Rocca MA, Hidalgo de La Cruz M, Valsasina $P$, et al. Two-year dynamic functional network connectivity in clinically isolated syndrome. Mult Scler 2019: 1352458519837704.

40. Lorscheider J, Buzzard K, Jokubaitis V, et al. Defining secondary progressive multiple sclerosis. Brain 2016;139:2395-2405.

41. Ceccarelli A, Rocca MA, Pagani E, et al. A voxel-based morphometry study of grey matter loss in MS patients with different clinical phenotypes. NeuroImage 2008;42:315-322. 


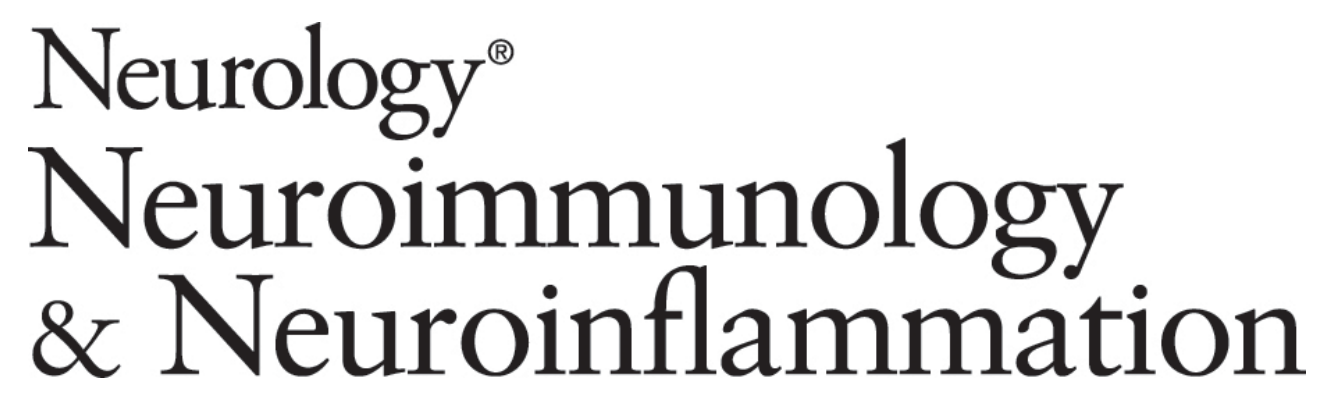

Network Damage Predicts Clinical Worsening in Multiple Sclerosis: A 6.4-Year Study Maria A. Rocca, Paola Valsasina, Alessandro Meani, et al.

Neurol Neuroimmunol Neuroinflamm 2021;8;

DOI 10.1212/NXI.0000000000001006

This information is current as of May 21, 2021

Neurol Neuroimmunol Neuroinflamm is an official journal of the American Academy of Neurology.

Published since April 2014, it is an open-access, online-only, continuous publication journal. Copyright

Copyright $\odot 2021$ The Author(s). Published by Wolters Kluwer Health, Inc. on behalf of the American

Academy of Neurology.. All rights reserved. Online ISSN: 2332-7812.

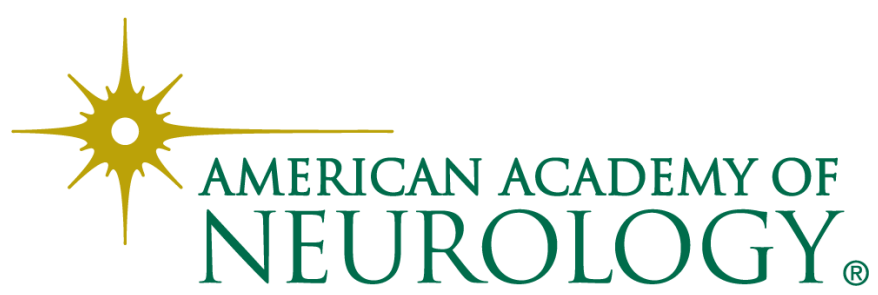




\section{Updated Information \& Services}

References

Citations

Subspecialty Collections

Permissions \& Licensing

Reprints including high resolution figures, can be found at: http://nn.neurology.org/content/8/4/e1006.full.html

This article cites 39 articles, 3 of which you can access for free at: http://nn.neurology.org/content/8/4/e1006.full.html\#\#ref-list-1

This article has been cited by 3 HighWire-hosted articles: http://nn.neurology.org/content/8/4/e1006.full.html\#\#otherarticles

This article, along with others on similar topics, appears in the following collection(s):

\section{fMRI}

http://nn.neurology.org//cgi/collection/fmri Multiple sclerosis

http://nn.neurology.org//cgi/collection/multiple_sclerosis

Prognosis

http://nn.neurology.org//cgi/collection/prognosis

Volumetric MRI

http://nn.neurology.org//cgi/collection/volumetric_mri

Information about reproducing this article in parts (figures,tables) or in its entirety can be found online at:

http://nn.neurology.org/misc/about.xhtml\#permissions

Information about ordering reprints can be found online: http://nn.neurology.org/misc/addir.xhtml\#reprintsus

Neurol Neuroimmunol Neuroinflamm is an official journal of the American Academy of Neurology.

Published since April 2014, it is an open-access, online-only, continuous publication journal. Copyright

Copyright $\odot 2021$ The Author(s). Published by Wolters Kluwer Health, Inc. on behalf of the American Academy of Neurology.. All rights reserved. Online ISSN: 2332-7812.

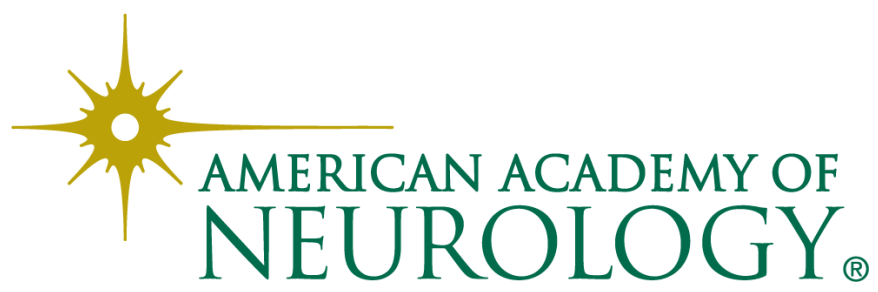

